\title{
Pattern of Hymenopteran Parasitoid Community in Oil Palm Plantations: Effects of Age Gradient or Sampling Methods?
}

\author{
Bandung Sahari $^{2 *}$, Ali Nurmansyah ${ }^{1}$, Syafrida Manuwoto ${ }^{1}$, Damayanti Buchori ${ }^{1}$ \\ ${ }^{1}$ Department of Plant Protection, Faculty of Agriculture, IPB University, Bogor, West Java 16680, Indonesia \\ ${ }^{2} \mathrm{PT}$ Astra Agro Lestari, Jakarta \\ *Corresponding author.Email: bandung_27@yahoo.com
}

\begin{abstract}
In oil palm plantations, there is age gradient that is expected to affect pattern of Hymenopteran parasitoid community. The aim of the research is to evaluate effects of age gradient of oil palm plantations on community of hymenopteran parasitoid. Approximately, six blocks representing three different ages of oil palm plantations ( $<3$ years, 6 years old, and 18 years old) were selected for parasitoid sampling. For each selected block, about five hectares were systematically selected. Samplings were conducted by surveying hymenopteran parasitoid inside the plantation in one ha for one hour transect walk. Insect collections were conducted using yellow pan trap and sweep-net along 30 days. Collected insects stored inside plastic container containing alcohol 70\% and brough into laboratory for sorting and identification. Overall, we sampled approximately 2440 specimens of Hymenopteran parasitoids belonging to 9 superfamilies, 14 families and 143 morphospecies. Braconidae, Scelionidae, and Ichneumonidae were the most abundant and specious families. Age gradient has a strong effect on species richness and species composition of hymenopteran parasitoid. Younger oil palm plantations support more species number and more similar species composition than older oil palm plantations. Sampling methods did not substantially affect community pattern of hymenopteran parasitoids.
\end{abstract}

Keywords: parasitoid, age gradient, oil palm, community

\section{INTRODUCTION}

Hymenopteran parasitoid is the most important group of parasitoid [1-4] that provides essential ecological services in agricultural landscapes by controlling pest population [2, 5]. The presence of a high level of diversity of Hymenopteran parasitoid can be thought of as having potential value to biological control projects [2]. Research on parasitoids associated with leaf-eating caterpillars in oil palm plantation in Indonesia has been well studied by many studies [6-8].

The success of biological control by using parasitoid in the field depends on the dynamic of parasitoid community, which is strongly affected by their habitat stability [7]. Agricultural landscape is a dynamic mosaic of vegetation type. It creates spatial dynamic and it changes by time to time creating temporal variation. Simplification of landscape have negative impact on biological control activity of natural enemies in agricultural landscape [10]. Different component of a landscape typically varies in their contribution to the species diversity in the ecosystem [11] including parasitoid community. Determination of what factor affecting the dynamic of parasitoid community is a crucial to develop appropriate strategy for biological control program.
In oil palm plantation, palms are planted gradually following the availability of land to be planted. Therefore, age gradient in oil palm plantation is commonly found, and understorey non crop vegetation change by increasing age of oil palm [7]. At the beginning, Mucona bracteata is planted as a cover crop, therefore this legume dominates the vegetation. Population of this species decreased by increasing age of oil palm and canopy cover, decreasing light intensity as well. It can be expected that this creates structural habitat complexity. Response of parasitoid may differ for different species or taxonomic in relation to changing habitat complexity. This will also affect services that are provided by existing parasitoid community.

The objectives of the research were to study the hymenopteran parasitoid inhabiting oil palm plantation and effects of age gradient on community of hymenopteran parasitoid in oil palm plantation.

\subsection{Materials and Methods}

\subsubsection{Insect sampling}

Approximately six blocks represented three different ages ( $<3$ years old, 6 years old, 18 years old) of oil palm 
plantations were selected to study effects of age gradient of oil palm plantations on hymenopteran parasitoid community. Within each block, about four plots were systematically selected for samplings. Size of one plot was about 1 ha. Insects were sampled by using sweep net following diagonal transect walks crossing the plot for about one hour. Samplings were only conducted between 07.00 and 11.00 Am. In addition, about four yellow pan traps were also set up inside the plot between 07.00 and 11.00 A.M. Insects samplings were conducted every day along 30 days. Insects were then collected inside plastic container containing alcohol $70 \%$ and brought into the laboratory for sorting and identification.

\subsubsection{Sorting of insect specimens}

First, insect samples were sorted to orders level. Then only Hymenopteran parasitoid were identified to families and sorted to morphospecies. Identification of parasitic wasps to families was conducted by using the family identification key of Goulet \& Huber (1993).

\subsubsection{Statistical analyses}

To calculate first-order jack knife estimates, we used the computer program of Colwell (2000) by not shuffling individuals among samples within species and randomizing samples 50 times. For quantifying the similarity of different samples, we pooled the samples from the 30 days insect collection per plot. As measure of similarity we calculated the frequently used Sørensen index. Based on Sørensen values we performed non-linear multidimensional scaling (MDS) which led to a two-dimensional projection of distances between the plots. Difference between observed blocks in relation with species richness and abundance was calculated with ANOVA. The computed ANOVA was always of a one-way type. Means are given with standard deviation if not mentioned otherwise. Scheffé test was used for multiple comparisons of means.

\subsection{Our Contribution}

This paper discusses pattern of Hymenopteran parasitoid in relation with age of oil palm and its effects on biological control. Therefore, the result if this research is very important as a foundation to formulation of pest control in oil palm plantations.

\subsection{Paper Structure}

The rest of the paper is constructed as follows: section 2 , serves description community structure of parasitoid in relation with age of oil palm dan sampling methods. 3 concludes the results of this paper.

\section{RESULTS AND DISCUSSION}

\subsection{Community of Hymenopteran parasitoid}

Many studies have reported hymenopteran parasitoid in oil palm plantations, especially those which related to lepidopteran pests of the palm [12-15]. However, how pattern of parasitoid community including species richness, diversity, and abundance under different age of oil palm plantations are poorly documented. In this study, we concentrated our work on assemblage of hymenopteran parasitoids inhabiting oil palm plantations under different age gradient

Overall, we sampled approximately 2440 specimens of Hymenopteran parasitoids belonging to 9 superfamilies, 14 families and 143 morphospecies. Species accumulation curve calculated for all samples and total number of estimated species by Chaol and Jackfnife 1 still increasing (Figure 1). The sampling efforts only detected $68.57 \%$ and $75.63 \%$ of species richness estimated by Chao1 and Jackknife-1, respectively. This indicates that the species assemblages of Hymenopteran parasitoids inside oil palm plantation are still very incompletely surveyed. Braconidae, Scelionidae, and Ichneumonidae were found to be the most abundant and specious families by occupying about 34.30 $\%, 26.23 \%$, and $15.37 \%$ of total collected specimen. However, Ichneumonidae was identified to be the most specious family with 35 species followed by Braconidae and Scelionidae with 29 and 21 morphospecies respectivelly (Figure 2).

From about 143 species, only 19 of which were identified to consist of more than 30 individuals. We created a ranking of those to figure out the most populated species inhabiting oil palm plantations. Scelionidae-5 was found to be the most abundant species, followed by Evaniidae, and Ascogaster (Figure 3). Most member of the family of Scelionidae act as egg parasitoids of Lapidopteran insects. Evaniidae-1 was recorded to be the second larger species. All member of family of Evaniidae are egg parasitoids of Blatodea [2], meanings that this species is not directly related to oil palm since member of Blattodea are not oil palm-related herbivorous insects.

\subsection{Effects of Age Gradient on the Pattern of Hymenopteran Parasitoids}

Species richness of Hymenopteran parasitoid inhabiting inside oil palm plantations varies between 32 and 79 species across different oil palm ages. Species richness recorded from younger oil palm plantation seems to have higher number of species than older oil palm plantations (Figure 4). Block A15 and OB6 with 81 and 79 respectivelly were identified to have higher species than other blocks. In contras Block E16 and E12 were found the support lower species (Figure 6 and 7)

Sørensen indices were used to quantify the similarity of species composition between sampled sites. The two- 
of Hymenopteran parasitoid recorded by observing oil palm plantation along 30 days.

Composition of dominant species varies between ages of oil palm plantations. Scelionidae was recorded to be the most dominant species flying around inside oil palm plantation. This can be seen from consistent occurrence across age of oil palm plantations. (Figure 7 and 8).

\subsection{Abundance Dynamic of Dominance Species of Hymenopteran Parasitoids}

From about 143 species of Hymenopteran parasitoid only few numbers of species consistently flying around inside oil palm plantation based on observation of 30 days. Abundance of Hymenopteran parasitoid species varies across ages of oil palm plantations. Occurrence of species from block E12 and E16 representing older oil palm plantations was not shown since there is no species with number of individuals reached 30 individuals. The worst is that less than 10 individual per species of dominant group

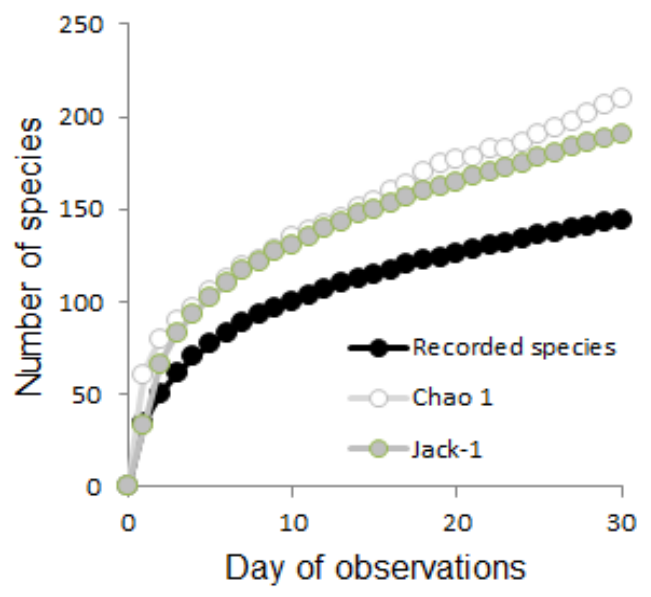

Figure 1 Species accumulation curve (recorded species) and Chao 1 and Jackknife estimates on the total number of expected species for the assemblage of Hymenopteran parasitoid species in the study area. Calculations are based on 30 samples $(1$ sample $=$ species assemblage recorded during one day of insect collection using sweep net and yellow pan trap of four plots per block) from different ages of oil palm plantations ( $<3$ years old, 6 years old, 18 years old)
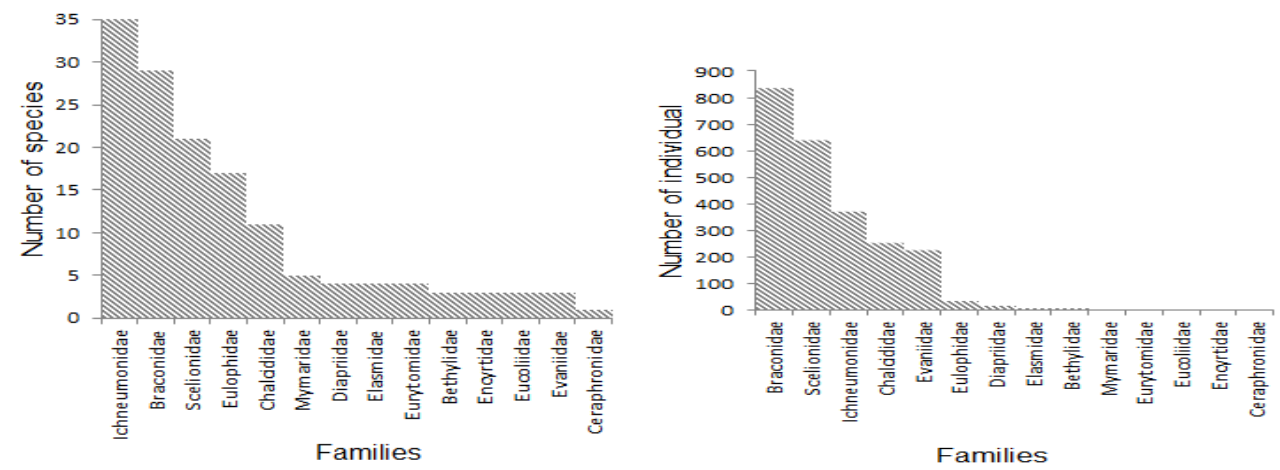

Figure 2 Species richness and abundance of families of Hymenopteran parasitoid community in oil palm. Specimens were collected by surveying parasitoids from 24 plots representing three different age of oil palm $(<3$ years old, 6 years old, and 18 years old) using yellow pan trap and sweep-net along 30 days 


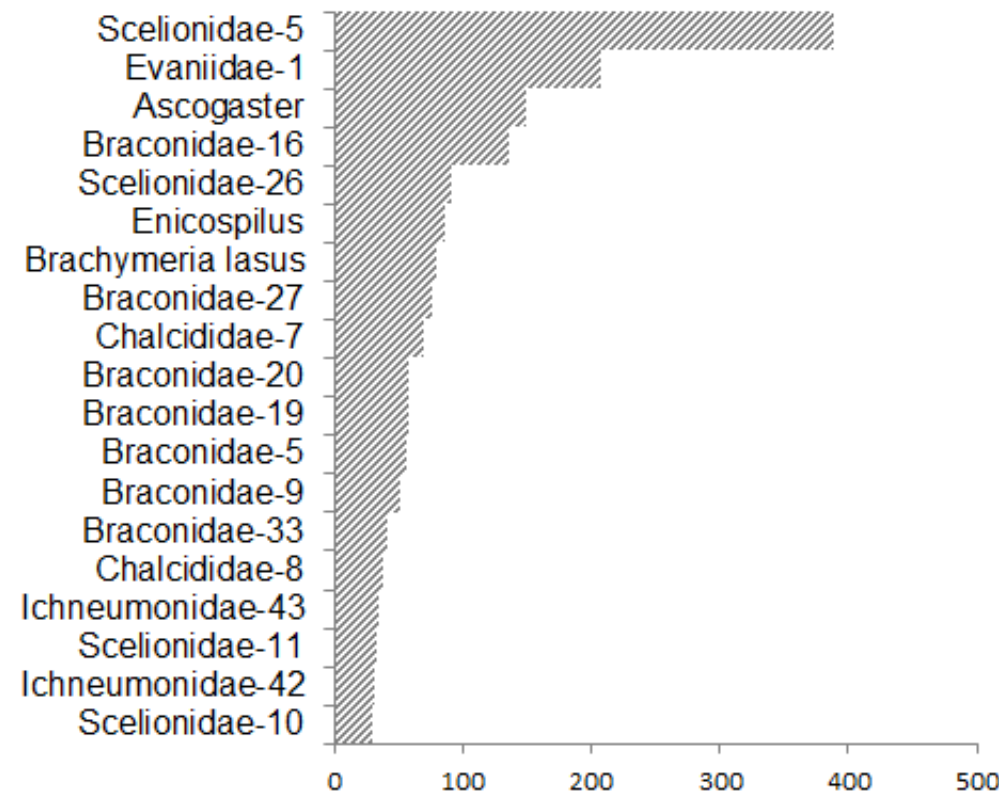

Number of individual

Figure 3 Abundance ranking of 19 species of Hymenopteran parasitoid in oil palm plantations. Speciments were collected by using sweep-net and yellow pan trap method from 24 plots representing three different ages of oil palm plantations ( $<3$ years, 6 years old, 18 years old) along 30 days. Only species with more than 30 individual calculated to determine the species ranking

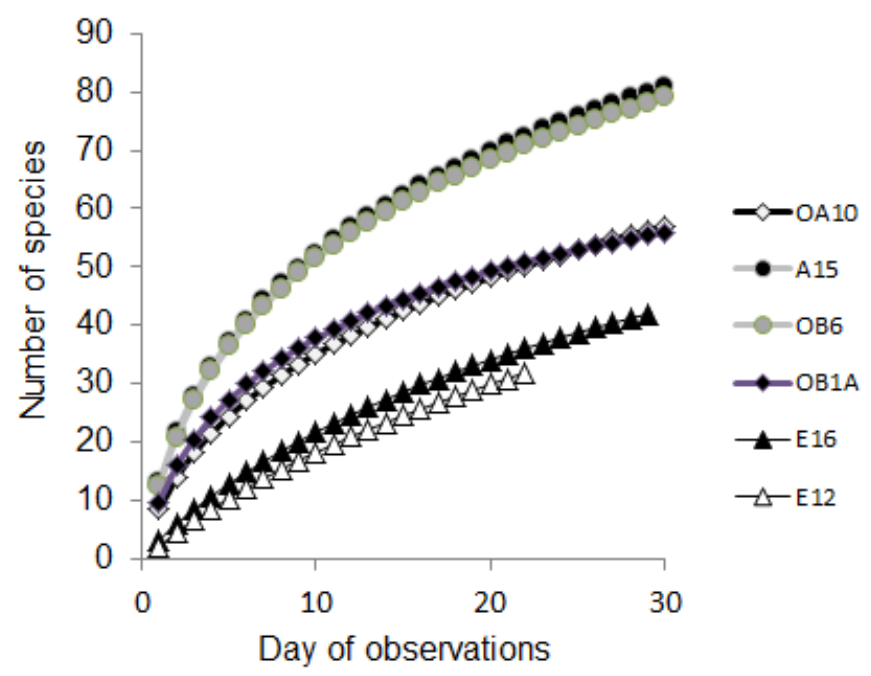

Figure 4 Species accumulation curve for the assemblage of flower-visiting Hymenopteran parasitoid species collected from six blocks representing three different ages of oil palm plantation $(<3$ years old, 7 years old, 16 years old) 


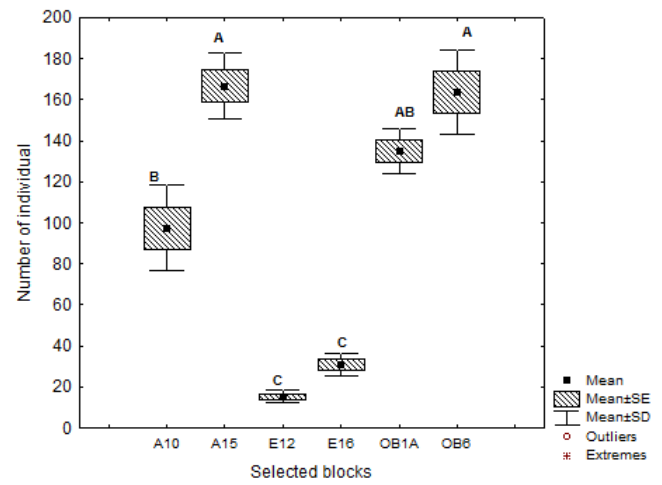

Figure 5 Species richness and abundance of hymenopteran parasitoid in oil palm plantations. Speciments were collected using yellow pan trap and sweep net $\left(\mathrm{N}=24\right.$; Species richness : $\mathrm{F}_{5,8}=58.21 ; \mathrm{P}<0.001 ;$ Abundance $\mathrm{F}_{5,8}=80.84$; $\mathrm{P}<0.001) .(<3$ years old= A10 \& A15; 6 years old=OB6 \& OB1A, 18 years old $=\mathrm{E} 12 \& \mathrm{E} 16)$

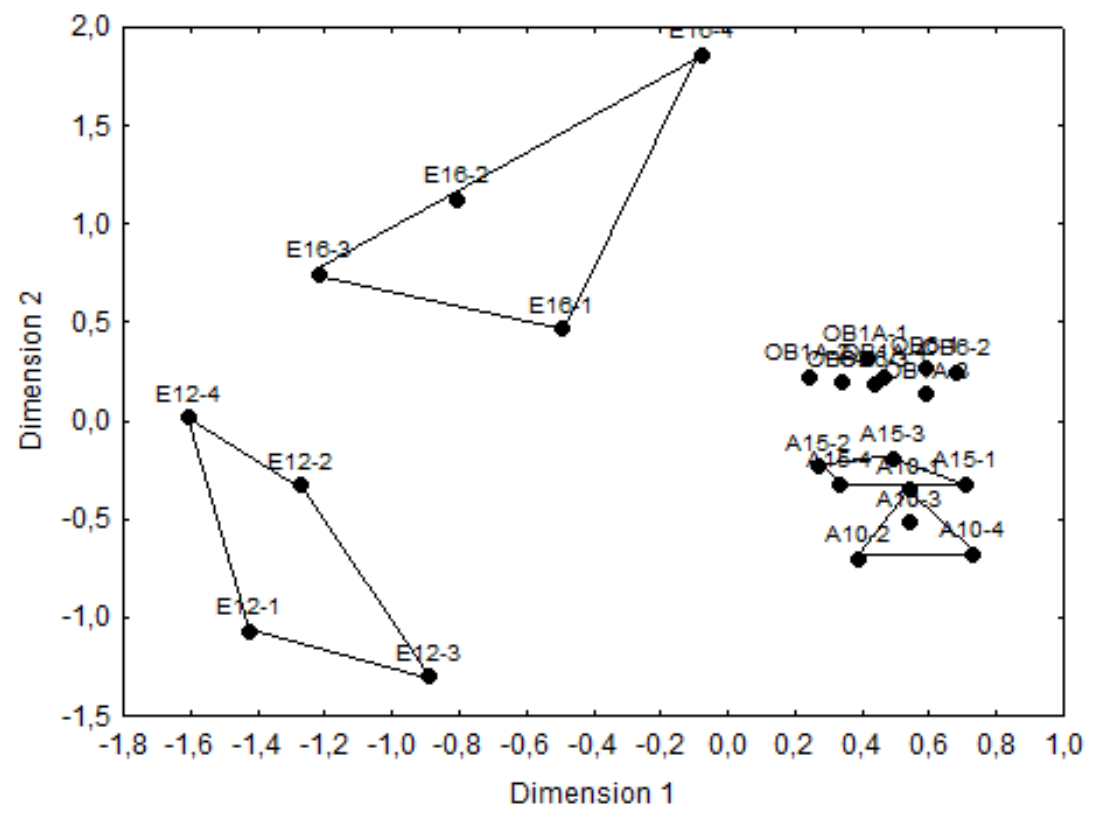

Figure 6 Two-dimensional scaling plot based on Sørensen indices for measuring similarity of species composition between single sampling plots. E: 18 years old oil palms; OB: 6 years old; A: <3 years old oil palm plantation. Connecting lines indicates defined groups of habitats

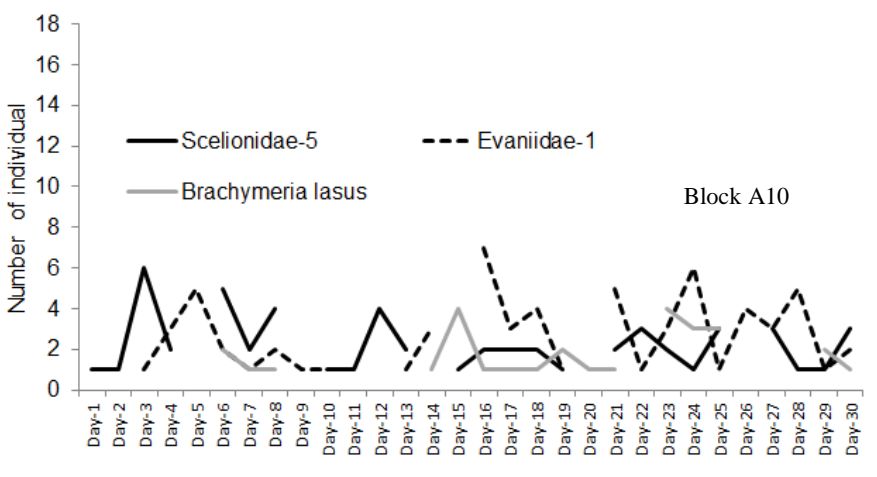

Day of observation

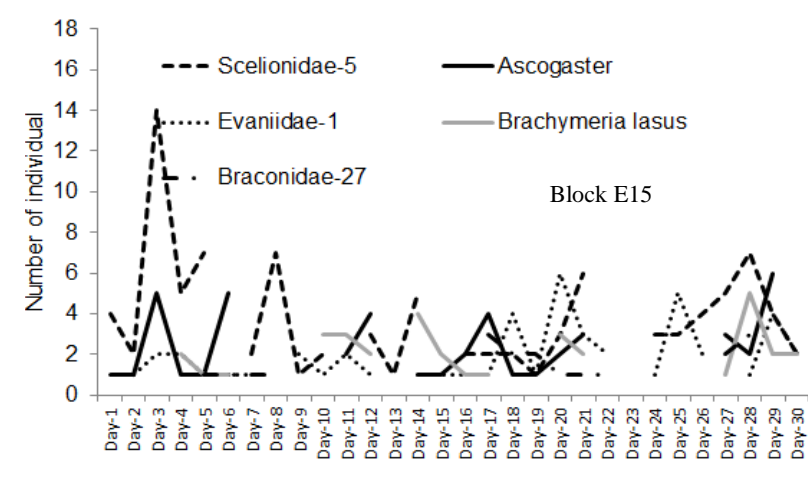

Day of observation

Figure 7 Abundance of Hymenopteran parasitoid species in young oil palm plantation (<3 years old). Only species with less then 30 individual showed 

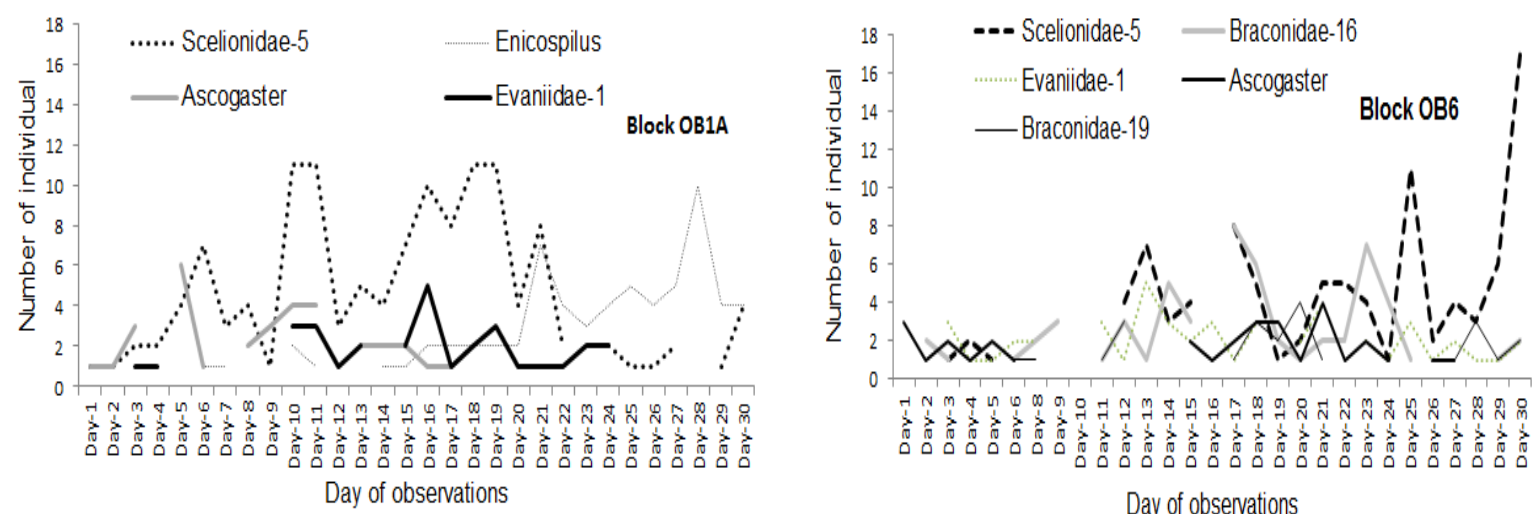

Day of observations

Figure 8 Abundance of Hymenopteran parasitoid species in seven years old oil palm plantation. Only species with less then 30 individual showed

\subsection{Effects of Sampling Methods on Com- munity Pattern of Hymenopteran Parasitoid}

Abundance structure of species with represented by more than 30 individual seems to be different for hymenopteran parasitoid community colected by different sampling method (Figure 9). Insect collection using sweep net recorded more species than yellow pan trap. Mean number of species richness $\left(\mathrm{N}=48 ; \mathrm{F}_{1.46}=0.25 ; \mathrm{P}=0.615\right)$ and individual $\left(\mathrm{N}=48 ; \quad \mathrm{F}_{1.46}=1.45 ; \mathrm{P}=0.23\right)$ collected using yellow pan trap and sweep net were not significantly different. Species composition of parasitoid community collected using different method was overlapped, indicated that species list recorded by yellow pan trap method seems to be similar with sweep net method (Figure 10).

Landscape is a function of space and time. In terms of space, the change of landscapes composition and habitat may bring about changes in the richness and composition of species in a given habitat. Spatial dynamic pattern of hymenopteran parasitoid was strongly affected by age gradient of oil palm plantations. This can be seen from two dimensional scaling plots that showed pronounced change of species composition across ages of oil palm plantations and species composition was found to be more similar between selected plots from younger oil palm plantations than older ones. This may be related to the different microclimatic condition and available non crop vegetation. Younger oil palm plantations which are characterized with more homogenic species of cover crop Mucuna bracteata. support more similar species of hymenopteran parasitoids. In contrast, older oil palm plantations with shading canopy will gradually eliminate $M$. bracteata and support more various species of weed to grow. This will bring a significant effect on microclimatic condition, humidity, light intensity, and temperature. Non crop vegetation holds a significant role in creating appropriate micro climatic condition and providing foods for adult parasitoids [10]. It is expected that change of species composition of parasitoid between ages of oil palm plantations, may also affect the control services provided by parasitoid species.

Factor influencing patterns in parasitoid assemblages area generally thought to relate to one of four main categories: (1) host characteristics such as food plant range, feeding niche, abundance, hairiness, gregariousness, and
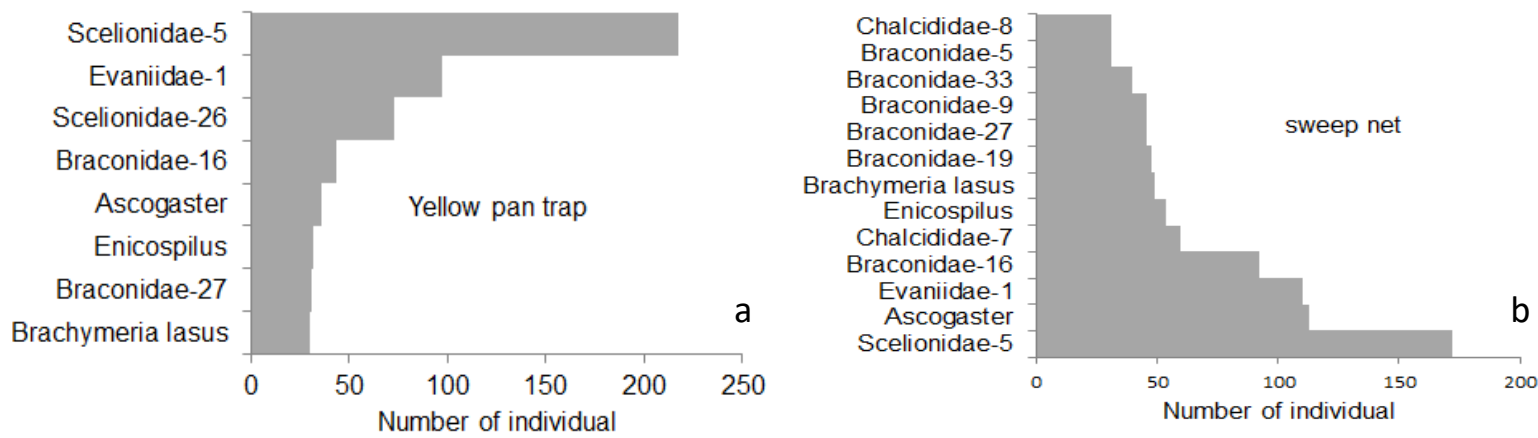

Figure 9 Abundance struturce of Hymenopteran parasitoid species collected by using yellow pan trap (a) and sweep net (b) methods from 24 plots representing three different age of oil palm plantations ( $<3$ years, 6 years, 18 years) along 30 days. Only species with more than 30 individual calculated to determine the species ranking 


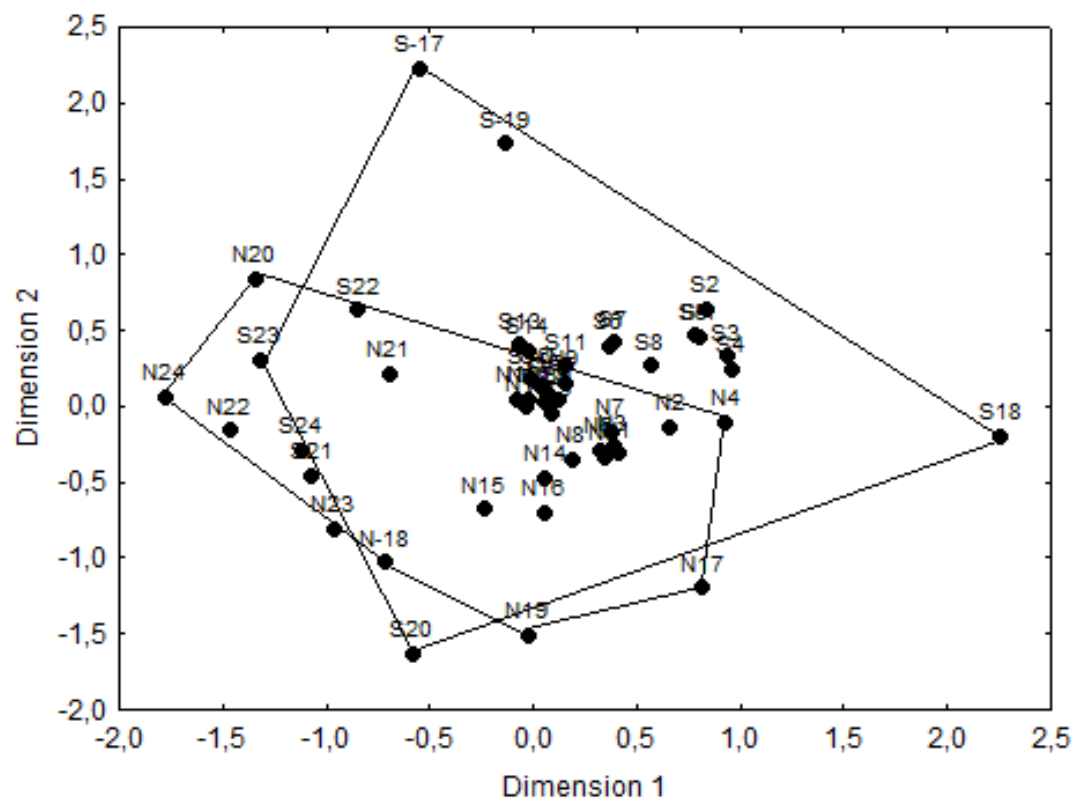

Figure 10 Two-dimensional scaling plot based on Sørensen indices for measuring similarity of species composition between single sampling plots. S: insect collection using sweep net, $\mathrm{N}$ : insect collection using yellow pan trap. Connecting lines indicates defined groups of sampling method

geographic range [7, 16] (2) ecological interaction [7, 18] (3) Habitat characteristics such as natural vs cultivated habitats and emergent characteristics including habitat stability and diversity [16], and (4) evolutionary templates including host phylogeny, successional stage of the host habitat, and associated anti-herbivore defence strategies [4]

Species composition is important indicator that can be used to measure the effect of habitat change $[17,19]$. What does the assemblage compose of? Are there a difference in the capability of each of the species with respect to pest control effectiveness and efficiency? The change of species composition may indicate that there are changes in the services that are delivered by the different composing species. It is true for insect pollinator as documented by [20, 21]. Sampling method seems not to affect species richness, abundance and species composition of hymenopteran parasitoid community.

\section{CONCLUSIONS}

In oil palm plantation, there is age gradient that would be expected to affect community of hymenopteran parasitoid. In this study, we found that age gradient has a strong effects on species richness and species composition of hymenopteran parasitoid. This will have a significant effects on natural control provided by hymenopteran parasitoid. Younger oil palm plantations support more species number and more similar species composition than older oil palm plantations. Sampling methods did not substantially affect community pattern of hymenopteran parasitoids.

\section{ACKNOWLEDGMENT}

The author thanks PT. Astra Agro Lestari to fund this research. We sincerely thank all field assistants and everyone at the Research and Development of PT. Astra Agro Lestari for its support during the research.

\section{REFERENCES}

[1] J.S. Noyes, M. Hayat, A review of the genera of Indo-Pacific Encyrtidae (Hymenoptera: Chalcidoidea), Bull. Br. Mus. nat. His. (Ent) 48 (1984)131-395

[2] J. LaSalle, Parasitic Hymenoptera, biological control and biodiversity. In LaSalle J, Gauld ID. (eds). Hymenoptera and Biodiversity. London: CAB International, 1993, pp 197-216

[3] D.L.J. Quicke, Parasitic Wasps. London: Chapman \& Hall, 1997.

[4] H.C.J. Godfray, Parasitoids: Behavioral and Evolutionary Ecology. New Jersey: Princeton University Press, 1994.

[5] F.L. Wäckers, Assessing the suitability of flowering herbs as parasitoid food sources: flower attractiveness and nectar accessibility, Biol. Control. 29 (2004) 307-314

[6] R. Desmier de Chenon, A. Sipayung, P.S. Sudharto, The Importance of natural enemies on Leaf-Eating Caterpillars in Oil Palm Plantations in 
[14] M.W. Basri, K. Norman, A.B. Hamdan, Natural

Sumatra, Indonesia. Paper presented in PORIM International Palm Oil Development Conference., 1989, pp 245-262

[7] B. Sahari, Struktur Komunitas Hymenoptera Parasitika di Lansekap Perkebunan Kelapa Sawit, Desa Pandu Senjaya, Pangkalan Lada, Kalimantan Tengah, Ph.D Thesis, IPB University, 2012

[8] B. Sahari, D. Buchori, S. Manuwoto, A. Nurmansyah, Pattern of Lepidopteran pest community attacking oil palms and their associated hymenopteran parasitoid. IOP Conference Series: Earth and Environmental Science 325 (1) (2019) 012010

[9] A. Rizali, S. Karindah, T. Himawan, M.L.T. Meiadi, B.T. Rahardjo, B. Sahari, Parasitoid wasp communities on oil palm plantation: Effects of natural habitat existence are obscured by lepidopteran abundance. J. Asia Pas. Entomol. 22 (3) (2019) 903-907

[10] D.J. Perofic, G.M. Gurr, A. Raman, H.I. Nicol, Effect of landscape composition and arrangement on biological control agents in a simplified agricultural system: a cost-distance approach, Biol. Control. 52 (2010) 263-270

[11] E. Fleishman, C.J. Betrus, R.B. Blair, Effects of spatial scale and taxonomic group on partitioning of butterfly and bird diversity in the Great Basin, USA, Lands. Ecol. 18 (2003) 675-685

[12] T. Sankaran, R.A. Syed, The natural enemies of bagworms on oil palms in Sabah, East Malaysia. Pacific Insect 14 (1972) 57-71

[13] R.G. Mexzon, C.M. Chincilla, An inventory of the oil palm pests and their natural enemies in Central America. PORIM International Palm Oil Conference, 1991, pp. 443-450. enemies of the bagworm Metisa plana (Lepidoptera: Psychidae) and their impact on host population regulation, J. Crop Prot. 14 (1995) 637 645.

[15] Y.L. Cheong, A.S. Sajab, N.M. Hafidzi NM, D. Omar, F. Abod, Outbreaks of bagworm and their natural enemies on an oil palm, Elaeis guineensis, plantation at Hutan Melintang, Perak, Malaysia, J Entomol 7 (2010) 141-151.

[16] B.A. Hawkins, Pattern and Process in HostParasitoid Interactions, London: Cambridge University Press, 1994.

[17] B. Sahari, A. Rizali, D Buchori, Insect Pollinator Communities under changing landuse in Tropical Landscapes: Implications for agricultural management in Indonesia. In Tropical Rainforests and Agroforests Under Global Environment Change, Springer, Berlin, 2010, pp. 97-114

[18] B. Sahari, A Rizali, A. Mardiastuti, D. Buchori, Case Study: Ecological Services Enhancing Agricultural Landscapes in Indonesia. In: Tropical Conservation: Perspectives on Local and Global Priorities. OXFORD University Press, 2017, pp. 385-389

[19] D. Buchori D, S. Puspitasari, B. Sahari, A. Rizali, A. Mardiastuti, Insect pollinator in decline: Conservation challenges in the tropics, In: Tropical Conservation: Perspectives on Local and Global Priorities. OXFORD University Press, 2017, pp. 290-300

[20] K.S. Delaplane, D.F. Mayer, Crop Pollination by Bees. CABI Publishing, New York, 2000.

[21] C. Kremen, N.M. Williams, R.W. Thorp, Crop pollination from native bees at risk from agricultural intensification. PNAS 99 (2002) $16812-16816$ 